\title{
Opportunistic infections in patients treated with immunotherapy for cancer
}

\author{
Chrisann Kyi ${ }^{1}$, Matthew D Hellmann ${ }^{2}$, Jedd D Wolchok ${ }^{3}$, Paul B Chapman ${ }^{2}$ and Michael A Postow ${ }^{2 *}$
}

\begin{abstract}
Immunomodulatory antibodies that enhance the immune system to fight cancer are revolutionizing the treatment of patients with an expanding variety of malignancies. There is a unique spectrum of side effects associated with immunomodulatory antibodies, termed immune-related adverse events (irAEs), which include colitis and hepatitis among others. The treatment of refractory or severe irAEs can occasionally require significant immunosuppression, involving steroids or tumor necrosis factor-alpha antagonists, placing these patients at risk for infections. We present the first reported case to our knowledge of an opportunistic infection in a patient treated with an immunomodulatory antibody. As the use of immunomodulatory antibodies expands and more patients develop irAEs that require treatment with immunosuppression, recognition of the potential for opportunistic infections in this emerging patient population will be critical. Prospective trials are needed to define the optimal immunosuppressive management of irAEs and determine whether prophylactic antiviral, antibacterial, or antifungal therapies are beneficial in this unique population.
\end{abstract}

Keywords: Immunotherapy, Immune-related adverse events (irAEs), Opportunistic infections, Malignancy, Melanoma, Ipilimumab

\section{Background}

T-cell checkpoint blockade is one of the most active areas of cancer research and has demonstrated dramatic results in patients with a variety of cancers [1-5]. Ipilimumab, an antibody against cytotoxic T-lymphocyteassociated antigen 4, was the first immunomodulatory checkpoint inhibitor approved by the US Food and Drug Administration for patients with advanced melanoma [1]. Programmed cell death-1 (PD-1) receptor, another immunologic checkpoint, has also shown great promise as a therapeutic target in a variety of malignancies [4-6].

T-cell checkpoint blockade can result in side effects called immune-related adverse events (irAEs), most commonly involving the skin (rash) and, particularly with ipilimumab, gastrointestinal tract (diarrhea, hepatitis). Refractory or severe irAEs often require treatment with prolonged immunosuppression including high-dose steroids and sometimes the addition of tumor necrosis factor-alpha blockade or other immunosuppressants [7]. We report a case of a patient with metastatic melanoma

\footnotetext{
* Correspondence: postowm@mskcc.org

${ }^{2}$ Memorial Sloan-Kettering Cancer Center, Melanoma and Immunotherapeutics Oncology Service, 300 East 66th Street, New York, NY 10065, USA

Full list of author information is available at the end of the article
}

who was treated with ipilimumab, developed immunemediated colitis requiring treatment with steroids and infliximab, and later developed an opportunistic infection with Aspergillus. This is the first case to be reported to our knowledge that specifically highlights the potential for developing opportunistic infections in this emerging patient population.

\section{Case presentation}

A 48-year-old Caucasian man was diagnosed with primary cutaneous melanoma in 1991 when he was noted to have a pigmented lesion on his posterior right neck. Subsequent biopsy showed Breslow depth $2 \mathrm{~mm}$ melanoma. No information about the presence or absence of ulceration was available. He underwent wide local excision with pathology demonstrating no residual disease. A sentinel lymph node biopsy was not pursued.

The patient remained free of disease for 20 years until the age of 68 when he developed new hypertension, prompting a renal ultrasound that showed normal kidneys. Two hepatic lesions were incidentally noted. A subsequent positron emission tomography (PET) scan demonstrated bilobar hepatic metastases and multiple pulmonary metastases concerning for metastatic disease. 
Core biopsy of a lesion in the right hepatic lobe confirmed metastatic melanoma. Mass-spectrometry genotyping (Sequenom) revealed no known mutations that affect the gene encoding serine-threonine protein kinase BRAF (e.g., the BRAF V600E mutation).

Three weeks later, the patient began treatment with ipilimumab (3 $\mathrm{mg} / \mathrm{kg})$. After three doses of ipilimumab (approximately two months of therapy), he developed significant diarrhea. Colonoscopy with biopsy showed active colitis. He received two doses of infliximab $(5 \mathrm{mg} / \mathrm{kg}$, separated by 9 days) and high-dose systemic corticosteroids (methylprednisolone $2 \mathrm{mg} / \mathrm{kg} /$ day for one day, followed by prednisone $1 \mathrm{mg} / \mathrm{kg} /$ day tapered over one month) with ultimate resolution of his diarrhea.

A computerized tomography (CT) scan three months after starting ipilimumab demonstrated response of pulmonary and hepatic metastases. However, new bilateral cavitary pulmonary consolidations were noted concerning for fungal pneumonia (Figure 1a-b). At this time, the patient had no cough, fever, shortness of breath, or other pulmonary symptoms. Bronchoscopy was performed and bronchoalveolar lavage revealed Aspergillus fumigatus pneumonia with a lavage fluid also positive for galactomannan. Voriconazole and liposomal amphotericin B treatment for a 14-day course resulted in ultimate radiographic improvement (Figure 1c). Although his response to ipilimumab lasted approximately six months, he later had disease progression and unfortunately passed away due to metastatic disease.

\section{Conclusions}

As the use of immunomodulatory antibodies that block T-cell checkpoints expands, so too may the complications associated with this treatment. The unique spectrum of immune-mediated toxicities from these agents has been well characterized and algorithms for suggested immunosuppression regimens have been developed. However, the potential for opportunistic infections to arise as a result of the immunosuppression necessary to treat an irAE has not previously been highlighted. Though we have chosen to describe this one illustrative case, we have observed additional cases at our institution, including patients with Fournier's gangrene and cytomegalovirus viremia. Clinicians across the spectrum of internal medicine must have a high degree of suspicion for the development of these rare infections as early recognition, diagnosis, and treatment are essential to achieve favorable clinical outcomes.

Consensus guidelines instruct clinicians on the prophylaxis and treatment of opportunistic infections arising in patients following hematopoietic stem cell transplantation [8]. As we learn more from patients treated with these

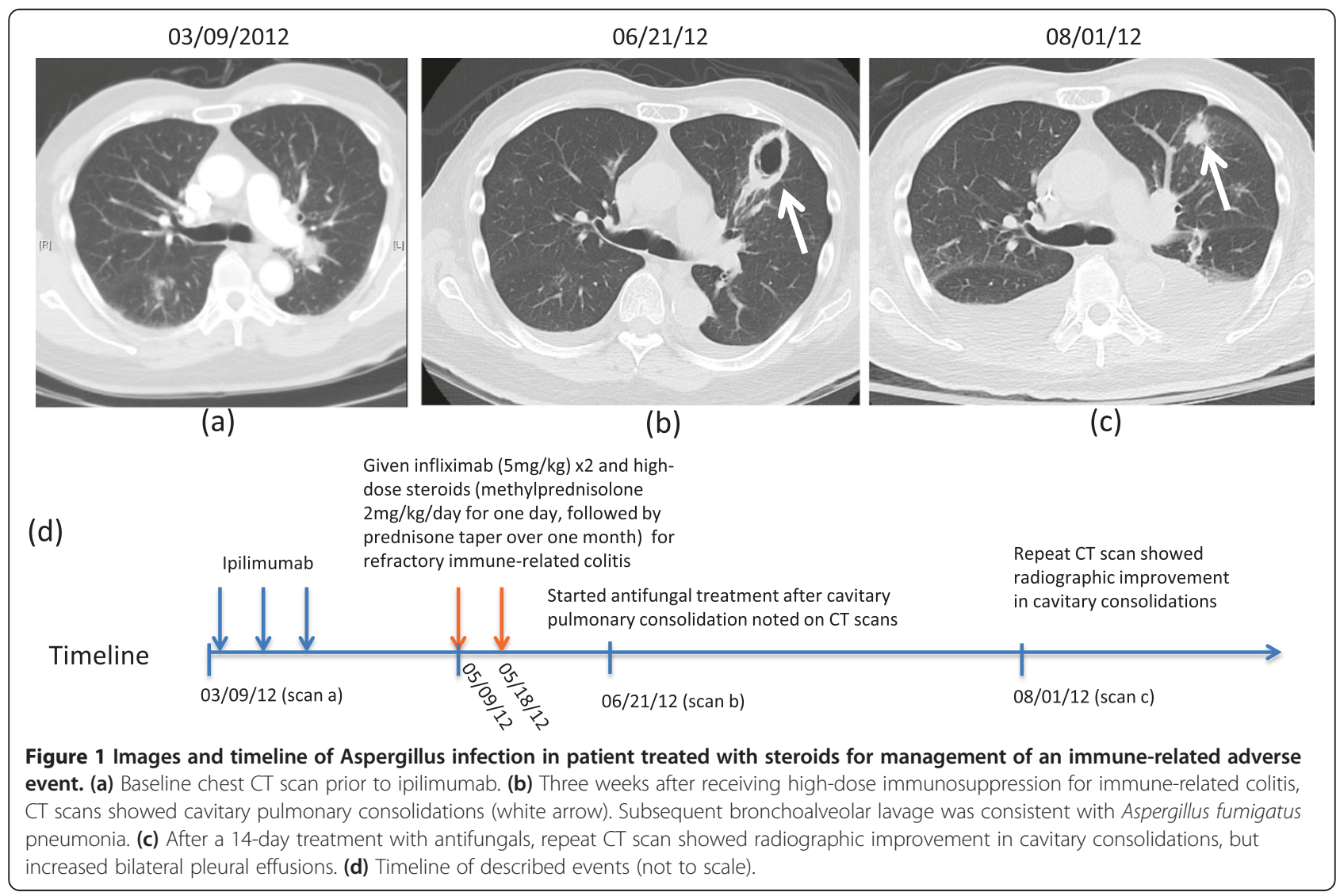


novel immunomodulatory antibodies, similar guidelines may be necessary to define the optimal management strategies for irAEs while also minimizing infectious complications in this unique patient population. Ultimately, prospective trials may be needed to optimize the management of irAEs, taking into account the associated secondary infectious risks.

\section{Consent}

Written informed consent was obtained from the patient's next of kin for publication of this case report and any accompanying images. A copy of the written consent is available for review by the Editor-in-Chief of this journal.

\section{Abbreviations}

CTLA-4: Cytotoxic T-lymphocyte-associated antigen 4; PD-1: Programmed cell death-1; irAE: Immune-related adverse event.

\section{Competing interests}

JDW and MP receive research support from Bristol-Myers Squibb and have served on advisory councils. $\mathrm{CK}, \mathrm{MDH}$, and PBC have no competing interests to disclose.

\section{Authors' contributions}

CK and MAP conceived of this study report, collected the data, wrote and revised the manuscript. $\mathrm{MH}$ conceived this study report concept and reviewed the manuscript. JDW and PBC reviewed the manuscript. All authors read and approved the final manuscript.

\section{Author details}

${ }^{1}$ New York-Presbyterian Hospital, Weill Cornell Medical College, 525 East 68th Street, New York, NY 10065, USA. ${ }^{2}$ Memorial Sloan-Kettering Cancer Center, Melanoma and Immunotherapeutics Oncology Service, 300 East 66th Street, New York, NY 10065, USA. ${ }^{3}$ Memorial Sloan-Kettering Cancer Center, 1275 York Avenue, New York, NY 10065, USA.

Received: 24 March 2014 Accepted: 14 April 2014

Published: 18 June 2014

\section{References}

1. Hodi FS, O'Day SJ, McDermott DF, Weber RW, Sosman JA, Haanen JB, Gonzalez R, Robert C, Schadendorf D, Hassel JC, Akerley W, van den Eertwegh AJ, Lutzky J, Lorigan P, Vaubel JM, Linette GP, Hogg D, Ottensmeier CH, Lebbe C, Peschel C, Quirt I, Clark JI, Wolchok JD, Weber JS, Tian J, Yellin MJ, Nichol GM, Hoos A, Urba WJ: Improved survival with ipilimumab in patients with metastatic melanoma. N Engl J Med 2010, 363:711-723.

2. Robert C, Thomas L, Bondarenko I, O'Day S, DJ M, Garbe C, Lebbe C, Baurain JF, Testori A, Grob JJ, Davidson N, Richards J, Maio M, Hauschild A, Miller WH Jr, Gascon P, Lotem M, Harmankaya K, Ibrahim R, Francis S, Chen TT, Humphrey R, Hoos A, Wolchok JD: Ipilimumab plus dacarbazine for previously untreated metastatic melanoma. N Engl J Med 2011, 364:2517-2526.

3. Hamid O, Robert C, Daud A, Hodi FS, Hwu WJ, Kefford R, Wolchok JD, Hersey P, Joseph RW, Weber JS, Dronca R, Gangadhar TC, Patnaik A, Zarour H, Joshua AM, Gergich K, Elassaiss-Schaap J, Algazi A, Mateus C, Boasberg P, Tumeh PC, Chmielowski B, Ebbinghaus SW, Li XN, Kang SP, Ribas A: Safety and Tumor Responses with Lambrolizumab (Anti-PD-1) in Melanoma. New Engl J Med 2013, 369:134-144.

4. Topalian SL, Hodi FS, Brahmer JR, Gettinger SN, Smith DC, McDermott DF, Powderly JD, Carvajal RD, Sosman JA, Atkins MB, Leming PD, Spigel DR, Antonia SJ, Horn L, Drake CG, Pardoll DM, Chen L, Sharfman WH, Anders RA, Taube JM, McMiller TL, Xu H, Korman AJ, Jure-Kunkel M, Agrawal S, McDonald D, Kollia GD, Gupta A, Wigginton JM, Sznol M: Safety, activity, and immune correlates of anti-PD-1 antibody in cancer. N Engl J Med 2012, 366:2443-2454.

5. Topalian SL, Sznol M, McDermott DF, Kluger HM, Carvajal RD, Sharfman WH, Brahmer JR, Lawrence DP, Atkins MB, Powderly JD, Leming PD, Lipson EJ, Puzanov I, Smith DC, Taube JM, Wigginton JM, Kollia GD, Gupta A, Pardoll DM, Sosman JA, Hodi FS: Survival, Durable Tumor Remission, and Long-Term
Safety in Patients With Advanced Melanoma Receiving Nivolumab. J Clin Oncol 2014, 32(10):1020-1030.

6. Weber JS, Kudchadkar RR, Yu B, Gallenstein D, Horak CE, Inzunza HD, Zhao X, Martinez AJ, Wang W, Gibney G, Kroeger J, Eysmans C, Sarnaik AA, Chen YA: Safety, efficacy, and biomarkers of nivolumab with vaccine in ipilimumabrefractory or -naive melanoma. J Clin Oncol 2013, 31:4311-4318.

7. Weber JS, Kahler KC, Hauschild A: Management of immune-related adverse events and kinetics of response with ipilimumab. J Clin Oncol 2012, 30:2691-2697.

8. Tomblyn M, Chiller T, Einsele H, Gress R, Sepkowitz K, Storek J, Wingard JR, Young JA, Boeckh MJ: Guidelines for preventing infectious complications among hematopoietic cell transplantation recipients: a global perspective. Biol Blood Marrow Transplant 2009, 15(10):1143-1238.

doi:10.1186/2051-1426-2-19

Cite this article as: Kyi et al.: Opportunistic infections in patients treated with immunotherapy for cancer. Journal for ImmunoTherapy of Cancer 2014 2:19.

\section{Submit your next manuscript to BioMed Central and take full advantage of:}

- Convenient online submission

- Thorough peer review

- No space constraints or color figure charges

- Immediate publication on acceptance

- Inclusion in PubMed, CAS, Scopus and Google Scholar

- Research which is freely available for redistribution 